\title{
Development and Optimization of Acyclovir Loaded Mucoadhesive Microspheres by Box - Behnken Design
}

\author{
J ames Regun Karmoker ${ }^{1}$, Ikramul Hasan ${ }^{2}$, Nusrat Ahmed ${ }^{1}$, Mohammad \\ Saifuddin ${ }^{3}$ and Md. Selim Reza ${ }^{2}$ \\ ${ }^{1}$ Department of Pharmacy, School of Medicine, University of Asia Pacific, Dhaka-1205, Bangladesh \\ ${ }^{2}$ Department of Pharmaceutical Technology, Faculty of Pharmacy, University of Dhaka \\ Dhaka-1000, Bangladesh \\ ${ }^{3}$ Department of Mathematics and Statistics, Bangladesh University of Business and Technology \\ Rupnagar, Mirpur-2, Dhaka-1216, Bangladesh
}

(Received: August 13, 2018; Accepted: December 12, 2018; Published (Web): April 01, 2019)

\begin{abstract}
The grail of the study was to design, develop and characterize sustained release mucoadhesive microspheres of acyclovir and to optimize the drug release profile using response surface methodology by applying Box-Behnken design (BBD) which was equipped with three levels and three factors. Microspheres were prepared from Methocel K15M and Ethocel Standard 45 Premium using the emulsification solvent evaporation technique. The independent factors were the amounts of Methocel $\mathrm{K} 15 \mathrm{M}\left(\mathrm{X}_{1}\right)$, amount of Ethocel Standard 45 Premium $\left(\mathrm{X}_{2}\right)$, and $\operatorname{RPM}\left(\mathrm{X}_{3}\right)$. The dependent variables were cumulative percentage drug release $(\mathrm{CDR})$ at 8 hour $\left(\mathrm{Y}_{1}\right)$, bond strength $\left(\mathrm{Y}_{2}\right)$, and swelling at 4 hour $\left(\mathrm{Y}_{3}\right)$. To understand the effects of different factor level combinations on the responses, various response surface graphs and contour plots were prepared. Predicted values and experimental values for optimized formulation $\left(X_{1}=600 \mathrm{mg}, X_{2}=500 \mathrm{mg}\right.$, and $\left.X_{3}=336.57\right)$ was found to be in close agreement.
\end{abstract}

Key words: Acyclovir, Box-Behnken Design, kinetic models, microspheres, mucoadhesion, optimization.

\section{INTRODUCTION}

After 1950s there has been an incessant turn down in the launch of new chemical moieties, the reasons could be many to name a few would be research and development costs which is escalating day by day, less number of organizations conducting pharmaceutical research, term of patent etc. It is estimated that the whole cycle involved in the marketing of a drug i.e., discovery, clinical phase, regulatory approval costs around $\$ 120$ million, estimated time could be around 10 years while drug delivery systems would cost around 40\%.' Drug delivery systems (DDS) have had a mammoth impact on the healthcare system due to its precise capacity to control the release rates or target drugs to a specific

Correspondence to: Md. Selim Reza

Tel: 880-2-9661900, Ext. 8182; Fax: 880-2-9667222

E-mail: selimreza@du.ac.bd

Dhaka Univ. J. Pharm. Sci. 18(1): 1-12, 2019 (June) DOI: https://doi.org/10.3329/dujps.v18i1.41421 body site. Microspheres constitute an important part of particulate DDS by virtue of their small size and efficient carrier characteristics despite having limitation due to their short residence time at the site of absorption. Therefore, by providing an intimate contact of the DDS with the absorbing membranes which can be achieved by coupling bioadhesion characteristics to microspheres would be

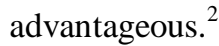

The development of an effective DDS, however, perpetually involves rational unification of a plethora of polymers and excipients. Optimizing the formulation composition and the manufacturing process of such a drug delivery product to embellish the desired quality persona is, therefore, a herculean task. The conventional approach of optimizing a formulation or process essentially involves studying 
the influence of one variable at time (OVAT), while keeping others as stable. Using this OVAT approach, the solution of a specific problematic property can be achieved somehow, but attainment of the true optimum composition or process is never guaranteed. ${ }^{3}$ In order to overcome most shortcomings inherent to the traditional OVAT approach, design of experiments (DoE), the holistic approach encircling the application of appropriate experimental designs coupled with the generation of mathematical equations and graphic outcomes, and depicting a complete picture of variation of the response(s) as a function of the factor(s), is being widely practiced. ${ }^{4}$ Of late, for formulation optimization, the response surface methodology (RSM), using proper DoE, has become extensively used. For understanding the effects of formulation variables (independent factors) and the reciprocal actions between factors on the responses (dependent factors), Box-Behnken design (BBD) is considered as one of the appropriate RSMs. In BBD, factors are usually taken at three levels and all the design points fall within the safe operating zone. BBD is still considered to be more proficient and most powerful than other designs such as the three-level full factorial design, central composite design (CCD) and doehlert design, despite its poor coverage of the corner of nonlinear design space. ${ }^{5,6}$ Moreover, it demands less experimental runs than three-level full factorial design and CCD, and is consequently less exclusive. To optimize the preparation of oral controlled release delivery systems $^{7}$ and sustained-release pellets, ${ }^{8}$ it has been productively used.

Acyclovir [9-(2-hydroxyethoxymethyl) guanine] $(\mathrm{ACV})$, is a synthetic purine nucleoside analog derived from guanine $\mathrm{e}^{9,10}$ which is considered as the first agent to be licensed for the treatment of herpes simplex virus (HSV-1, HSV-2) infections and is the most widely used drug for infections such as cutaneous herpes, genital herpes, chicken pox, varicella zoster infections through interfering with DNA synthesis and inhibiting viral replication. ${ }^{11-13}$ According to the Biopharmaceutical Classification System (BCS), ACV falls under the BCS Class III drug i.e. soluble with low intestinal permeability and needs to be administered in large doses orally or intravenously to obtain the desired therapeutic effect. ${ }^{14}$ ACV is almost completely unionized, has maximum solubility $2.5 \mathrm{mg} / \mathrm{ml}$ at $\mathrm{pH} 7.0$, soluble in acidic $\mathrm{pH}$ and is predominantly absorbed from the upper gastrointestinal tract (GIT). ACV is currently marketed as capsules (200 mg), tablets (200, 400 and $800 \mathrm{mg}$ ) and topical ointment. Oral acyclovir is typically used as $200 \mathrm{mg}$ tablets, five times a day. In addition, for immunocompromized patients with relapsing herpes simplex infection, long-term administration of acyclovir (6 months or longer) are required. The currently available conventional therapy is coupled with a number of limitations such as highly variable absorption and low bioavailability (10-20\%) after oral administration. Moreover, decrease in bioavailability was observed when dose is increased. Furthermore, because the mean plasma half-life of the drug is $2.5 \mathrm{~h}$, five times a day administration is required which causes compliance problems to patients. ${ }^{11,15}$

Therefore, the aim of the study was to develop mucoadhesive sustained-release formulations of ACV in the form of microspheres using BBD in combination with a desirability function and to evaluate the main effects of formulation variables on three responses: cumulative percentage of drug release at 8 hour, bond strength and swelling at 4 hour.

\section{MATERIAL AND METHODS}

Materials. Acyclovir was supplied from Incepta Pharmaceuticals Ltd. (Dhaka, Bangladesh). Ethocel standard 45 premium and Methocel K-15M were obtained from Colorcon Asia Pvt. Ltd, USA. Ethanol, Dichloromethane (DCM), sorbitanmonooleate (Span 80), heavy liquid paraffin and n-hexane were supplied by Merck, Germany. All other chemicals were of analytical grade.

Preparation of acyclovir microspheres. The method of preparation of acyclovir microspheres was based on emulsion solvent evaporation method using two different polymers: Ethocel Standard 45 premium and Methocel K15M. Weighed quantities of 
polymers were dissolved in $20 \mathrm{ml}$ solvent mixture (DCM:Ethanol =1:1). Then the required amount of acyclovir was added and dissolved by vortexing and sonication until a clear solution was formed. This solution was the internal phase. For the preparation of external phase, $50 \mathrm{ml}$ heavy liquid paraffin emulsified with $1 \mathrm{ml}$ Span 80 was taken in a $500 \mathrm{ml}$ beaker and stirred using a stirrer. The internal phase was then slowly poured drop by drop to the external phase, while stirring at required $\mathrm{rpm}$ held by the mechanical stirrer equipped with a three-blade propeller, at room temperature. The whole system was stirred for 3 hours. After that the microspheres were separated by filtration, the excess of paraffin oil was eliminated by repeated washing (3 times) with $\mathrm{n}$-hexane $(50 \mathrm{ml})$ and finally dried overnight at room temperature to yield free flowing spherical products. ${ }^{16-18}$

Box-Behnken experimental design. To explore and optimize the main effects, quadratic effects, and interaction effects of the formulation ingredients on the performance of the mucoadhesive micorspheres, a three-factor, three-level BBD was used. In such settings, to determine the experimental error and the precision of the design, $\mathrm{BBD}$ requires 15 experimental runs with three central points. ${ }^{5}$ Using Design-Expert software (V. 7.0.0.1; Stat-Ease Inc., Minneapolis, Minnesota), a total of 15 experimental runs were generated and evaluated. The major response factors used to evaluate the quality of the microspheres formulation, including cumulative percentage drug release $(\mathrm{CDR})$ at 8 hour $\left(\mathrm{Y}_{1}\right)$, bond strength $\left(\mathrm{Y}_{2}\right)$, and swelling at 4 hour $\left(\mathrm{Y}_{3}\right)$, were determined (Table 1). The selected factors with the actual and coded levels according to the design are represented in table 1 and 2 . The results obtained for each response were fitted to a quadratic polynomial model explained by a nonlinear Eq. (1):

$y=\beta_{0}+\beta_{1} X_{1}+\beta_{2} X_{2}+\beta_{3} X_{3}+\beta_{4} X_{1} X_{2}+\beta_{5} X_{2} X_{3}+$ $\beta_{6} X_{1} X_{3}+\beta_{7} X_{1}^{2}+\beta_{8} X_{2}^{2}+\beta_{9} X_{3}^{2}$

Here, $y$ represents the measured response, $\beta_{0}-\beta_{9}$ are regression coefficients and $X_{1}, X_{2}$, and $X_{3}$ are independent factors. By applying analysis of variance (ANOVA), lack of fit, and coefficient of determination $\left(\mathrm{R}^{2}\right)$ as a measure of goodness of fit of the fitted model, models were validated.

Table 1. Variables used in the Box-Behnken design.

\begin{tabular}{lccc}
\hline & \multicolumn{3}{c}{ Levels, actual (Coded) } \\
\cline { 2 - 3 } & Low $(-1)$ & Medium $(0)$ & High $(+1)$ \\
\hline Independent variables & & & 600 \\
$\mathrm{X}_{1}$ : Amount of Methocel K15M (mg) & 400 & 500 & 500 \\
$\mathrm{X}_{2}$ : Amount of Ethocel Standard 45P (mg) & 400 & 450 & 400 \\
$\mathrm{X}_{3}$ : RPM & 300 & 350 & Goals \\
\hline & & & Minimize \\
\hline Dependent variables & & Maximize \\
$\mathrm{Y}_{1}$ : CDR at 8 hour $(\%)$ & Minimize \\
$\mathrm{Y}_{2}$ : Bond strength $\left(\mathrm{N} / \mathrm{m}^{2}\right)$ & & \\
$\mathrm{Y}_{3}$ : Swelling at 4 hour $(\%)$ & & \\
\hline
\end{tabular}

Optimization using the desirability function. To optimize manifold responses, they should be highly interconnected with each other. It is improbable that the values enviable to optimize the effect of one response will have same effect on the second response, thus a variance can occur between them. Hence, the most favorable compromising zone must be required for each of the responses devoid of any bias. In the current study, all the responses were concurrently optimized by a desirability function that uses the numerical optimization method introduced by Derringer and Suich in the Design-Expert software (Stat-Ease Inc.). ${ }^{19}$ Recently, for the optimization of multiple responses, desirability function approach was reported in several articles. 5,8 
In vitro dissolution study. The dissolution studies of the microspheres were carried out in a type I USP dissolution test apparatus (Basket type). Weighed quantities of microspheres (equivalent to 20 $\mathrm{mg}$ of acyclovir) from each batch were placed in 900 $\mathrm{ml}$ of dissolution medium $(0.1 \mathrm{~N} \mathrm{HCl}$ of $\mathrm{pH} 1.2)$ and were stirred at $100 \mathrm{rpm}$ at $37 \pm 0.5^{\circ} \mathrm{C} .{ }^{9,20} \mathrm{~A} 10 \mathrm{ml}$ aliquot was withdrawn from the dissolution medium at pre-determined intervals of $1^{\text {st }}$ hour, $2^{\text {nd }}$ hour, $3^{\text {rd }}$ hour, $4^{\text {th }}$ hour, $5^{\text {th }}$ hour, $6^{\text {th }}$ hour, $7^{\text {th }}$ hour and $8^{\text {th }}$ hour. At each interval, the withdrawn medium was replaced with an equivalent amount $(10 \mathrm{ml})$ of fresh dissolution medium to maintain sink condition. Collected samples were analyzed by measuring the absorbance through an UV spectrophotometer at 255 $\mathrm{nm}$ after filtration and suitable dilution to determine the amount of the acyclovir released from the microspheres. The percentage of drug release was plotted against time. Each experiment was repeated three times. To find percentage of release, the average of the percentage of release was calculated for each batch.

Table 2. Experimental matrix and observed responses from randomized runs in the BBD.

\begin{tabular}{|c|c|c|c|c|c|c|}
\hline \multirow[t]{2}{*}{ Run } & \multicolumn{3}{|c|}{ Independent variables } & \multicolumn{3}{|c|}{ Dependent variables } \\
\hline & $\mathrm{X}_{1}$ & $\mathrm{X}_{2}$ & $\mathrm{X}_{3}$ & $\begin{array}{c}\mathrm{Y}_{1} \\
(\text { mean } \pm \mathrm{SD}, \mathrm{n}=3)\end{array}$ & $\mathrm{Y}_{2}$ & $\begin{array}{c}\mathrm{Y}_{3} \\
(\text { mean } \pm \mathrm{SD}, \mathrm{n}=3)\end{array}$ \\
\hline 1 & 0 & 1 & 1 & $81.27 \pm 0.89$ & 142.75 & $189.37 \pm 1.65$ \\
\hline 2 & -1 & 1 & 0 & $86.77 \pm 1.01$ & 181.92 & $212.48 \pm 3.56$ \\
\hline 3 & -1 & 0 & -1 & $88.18 \pm 1.00$ & 112.87 & $215.75 \pm 1.25$ \\
\hline 4 & 0 & 0 & 0 & $85.16 \pm 0.89$ & 167.98 & $200.68 \pm 1.77$ \\
\hline 5 & 0 & 0 & 0 & $84.32 \pm 0.76$ & 159.35 & $198.55 \pm 4.84$ \\
\hline 6 & 0 & -1 & -1 & $86.22 \pm 1.02$ & 146.07 & $202.99 \pm 2.43$ \\
\hline 7 & 1 & 1 & 0 & $69.15 \pm 0.90$ & 187.23 & $174.02 \pm 4.05$ \\
\hline 8 & 1 & 0 & 1 & $76.31 \pm 0.90$ & 136.11 & $182.58 \pm 3.68$ \\
\hline 9 & 0 & 1 & -1 & $77.72 \pm 1.39$ & 156.03 & $186.65 \pm 2.32$ \\
\hline 10 & -1 & -1 & 0 & $97.10 \pm 1.00$ & 126.81 & $301.54 \pm 1.85$ \\
\hline 11 & 1 & -1 & 0 & $79.31 \pm 1.12$ & 167.98 & $187.21 \pm 3.69$ \\
\hline 12 & -1 & 0 & 1 & $92.38 \pm 0.90$ & 120.17 & $220.04 \pm 2.37$ \\
\hline 13 & 0 & 0 & 0 & $86.08 \pm 1.00$ & 177.27 & $202.90 \pm 4.42$ \\
\hline 14 & 1 & 0 & -1 & $73.86 \pm 1.13$ & 146.73 & $181.72 \pm 1.75$ \\
\hline 15 & 0 & -1 & 1 & $87.48 \pm 1.01$ & 128.80 & $213.27 \pm 3.72$ \\
\hline
\end{tabular}

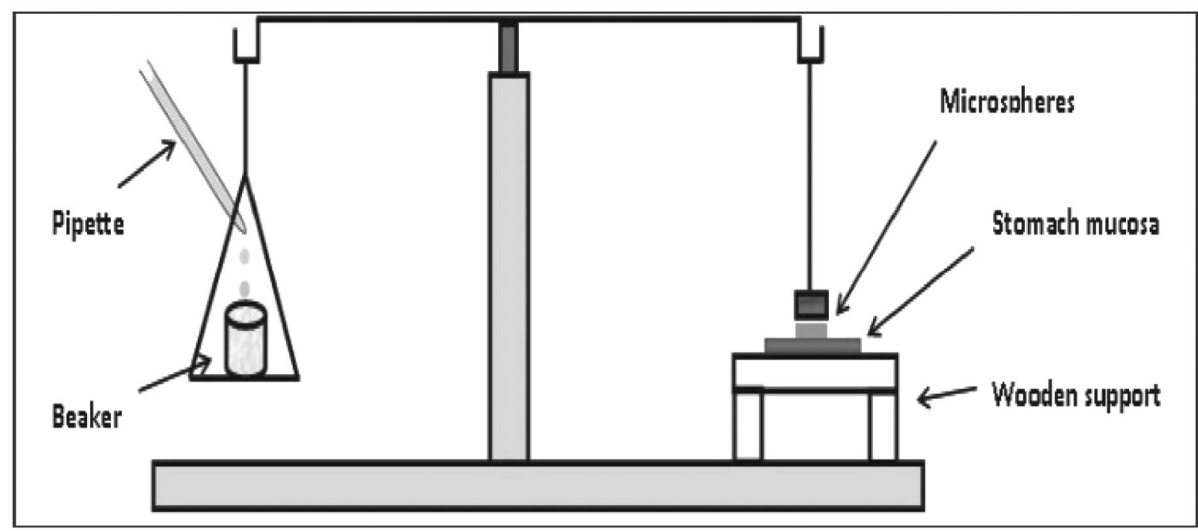

Figure 1. Determination of mucoadhesive strength by modified balance method. 
Ex-vivo mucoadhesion test. A modified balance method (Figure 1), adopted from Kyada et al. was used for determining the mucoadhesive strength. ${ }^{9}$ Fresh goat intestinal mucosa was obtained from a local slaughterhouse and used within 2 hours of slaughter. By removing the underlying fat and loose tissues, the mucosal membrane was separated. The membrane was washed with distilled water and then cut into pieces. Two pieces of goat stomach mucosa were pasted to the bottom of two glass vials with cyanoacrylate adhesive separately. From that one glass vial was fixed on the surface of the wooden support and other piece was tied with the balance on left hand side. A glass beaker was kept on right hand side. The right and left sides were balanced by adding extra weight on both the left and right hand side. Approximately $100 \mathrm{mg}$ of microspheres from each batch was placed between these glass vials containing goat stomach mucosa, and 3 drops of $0.1 \mathrm{~N} \mathrm{HCl}$ of $\mathrm{pH}$ 1.2 were added on it for wetting. Then, two vials were gently pressed to remove the presence of air. The balance was kept in this position for 5 minutes. As the quantity of microspheres was less, microspheres formed the monolayer along the surface of disk. Water was added slowly at $1 \mathrm{ml} / \mathrm{min}$ to the right-hand pan until the microsphere detached from the goat stomach mucosal membrane. The water in $\mathrm{ml}(1 \mathrm{ml}$ equivalent to 1 gram) required to detach the microspheres from the mucosal surface gave the measure of mucoadhesive strength. ${ }^{9} \quad$ The mucoadhesive strength was calculated using Eq. (2) and (3):

Force of adhesion $(\mathrm{N})=$ [mucoadhesion strength $(\mathrm{gm}) \times 9.81] / 1000$

Bond strength $\left(\mathrm{N} / \mathrm{m}^{2}\right)=$ force of adhesion / surface area of the bottom of vial

Swelling measurement. Microspheres were studied for swelling characteristics. Approximately $100 \mathrm{mg}$ drug-loaded microspheres from each batch were placed separately in a vessel containing $100 \mathrm{ml} 0.1 \mathrm{~N}$ $\mathrm{HCl}$ of $\mathrm{pH} 1.2$ and temperature maintained at $37 \pm$ $0.5^{\circ} \mathrm{C}$. The microspheres were periodically removed at pre-determined intervals of $1^{\text {st }}$ hour, $2^{\text {nd }}$ hour, $3^{\text {rd }}$ hour, $4^{\text {th }}$ hour and $5^{\text {th }}$ hour and weighed after removing excess water with the help of filter paper. ${ }^{21}$ Then, the swelling percentage was calculated as per the Eq. (4):

$\%$ Swelling $=[($ Final weight - Initial weight $) \times 100] /$ Initial weight

\section{RESULTS AND DISCUSSION}

In vitro dissolution study. It has been found (Table 2) that the rate of drug release from the microspheres depends on the polymeric concentration and indicated that the release rate decreased with the increasing amount of polymer. The decrease in release rate with increasing polymeric concentration can be described by a decreased amount of drug present close to the surface and also by the fact that with the increasing of polymer concentration the amount of uncoated drug decreases. Release data were analyzed with statistical level of significance ( $\alpha$ $=0.05$ ) and they were found statistically significant since in every case " $p$ " value was found less than 0.05 . Moreover, increased polymeric concentration as well as high viscosity of the spheres also contributes to lower drug release. Here, in some cases for two different batches having the same polymeric concentration showed different pattern of drug release. RPM could be a probable reason for such characteristics. When RPM is decreased, sizes of the spheres are increased that causes an increase in porosity, facilitate more diffusion and finally results in increased drug release. ${ }^{22,23}$ RPM can also contribute in other way around on drug release. With decreasing RPM, size is increased as a result surface area is decreased that slows the burst release and minimizes the drug release.

Ex vivo mucoadhesion test. The data for mucoadhesive strength in gm (mean $\pm \mathrm{SD}, \mathrm{n}=3$ ) for run 1 to run 15 were found to be $7.17 \pm 0.21,9.13 \pm$ $0.35,5.67 \pm 0.25,8.43 \pm 0.45,8.00 \pm 0.46,7.33 \pm$ $0.35,9.40 \pm 0.36,6.83 \pm 0.25,7.83 \pm 0.35,6.37 \pm$ $0.25,8.43 \pm 0.35,6.03 \pm 0.35,8.90 \pm 0.20,7.37 \pm$ 
$0.40,6.47 \pm 0.35$, respectively whereas bond strength in $\mathrm{N} / \mathrm{m}^{2}$ was reported in table 2. The range for mucoadhesive strength of run 1 to 15 was found to be $5.67 \pm 0.252$ to $9.40 \pm 0.361$ gram. Results showed that at highest polymeric concentration (e.g. $1100 \mathrm{mg}$ for run 7), bond strength $\left(\mathrm{N} / \mathrm{m}^{2}\right)$ was maximum. The order of bond strength of fifteen formulations also depicts that Methocel K15M played an important role in the matrix mucoadhesion as everywhere concentration of Methocel K15M was higher than corresponding Ethocel standard 45P except run 2. Methocel K15M, one of the most widely used mucoadhesive materials, has the capacity to generate carboxyl groups which facilitate the formation of hydrogen bonds with mucus.

Several studies have demonstrated that acyclovir is absorbed paracellularly by passive diffusion in the gastrointestinal tract and its poor solubility results in low oral bioavailability. ${ }^{15,24-26}$ Many in vitro everted sac and in situ single-pass perfusion experiments showed that absorption of acyclovir in the gastrointestinal tract primarily takes place at the upper and middle part of gastrointestinal tract. Hence, it is an efficient way to enhance the bioavailability of acyclovir by introducing gastro retentive dosage form which can enable continuous drug delivery to the upper part of the gastrointestinal tract. It has been reported that incorporation of mucoadhesive materials into microspheres significantly increase the gastrointestinal transit time of microspheres. ${ }^{2,9}$

Swelling measurement. As shown in table 2, the microspheres from run 7 exhibited lowest percentage swelling (174.02\%) at 4 hour while the highest swelling was noticed in run 10 (301.54\%). Maximum swelling for microspheres was reached at 4 hour, after which erosion or breakdown took place since most of the formulations showed less percentage swelling at the $5^{\text {th }}$ hour in comparison with their corresponding percentage swelling at $4^{\text {th }}$ hour. Md et al. experienced same sort of swelling behavior for acyclovir in acidic medium. ${ }^{21}$

This effect might be due to the acid solubility of drug that might have influenced the swelling behavior of the microspheres. These results also demonstrate that polymeric concentration in the formulation maintains a reciprocal relationship with percentage swelling of that formulation. It has been previously reported that the higher the swelling of the polymers, the higher is the drug release from the microspheres. ${ }^{21}$

Box-Behnken statistical analysis. A 3-factor, 3level BBD requires 15 experimental runs. Based on the experimental runs generated at different factor level combinations, a series of experiments was performed. In table 2, the experimental matrix from the randomized runs for the independent variables and responses observed is exposed. Ten batches showed $\%$ CDR $\left(\mathrm{Y}_{1}\right)$ of microspheres greater than 80 $\%$ and the range of $\mathrm{Y}_{1}$ for all batches was $69.15 \%$ $97.10 \%$. Similarly, the range for bond strength $\left(\mathrm{Y}_{2}\right)$ was $187.23-112.87 \mathrm{~N} / \mathrm{m}^{2}$ and the percentage swelling at 4 hour $\left(\mathrm{Y}_{3}\right)$ was $174.02 \%-301.54 \%$.

All responses were fitted to a second quadratic model and the adequacy of this model was verified by ANOVA, lack of fit and coefficient of determination $\left(R^{2}\right)$ tests. The results of lack of fit tests and ANOVA of the quadratic models for all responses are revealed in table 3. Here, in the ANOVA test, the $p$ values of F-statistic of the model for responses $\mathrm{Y}_{1}, \mathrm{Y}_{2}$ and $\mathrm{Y}_{3}$ were $0.0003,0.0252$, and 0.0495 respectively. As a consequence, from the $p$ values for this model it can be accomplished that all of the responses $\left(\mathrm{Y}_{1}, \mathrm{Y}_{2}\right.$ and $\mathrm{Y}_{3}$, ) fitted the quadratic model well $(p<0.05)$. Moreover, the lack of fit test is another excellent statistical parameter for checking better fitness of the model. It juxtaposes the residual error to the pure error from the replicated design points. A model with a significant lack of fit ( $p$ value $>0.10$ or smaller) lacks prediction efficiency, so a non-significant lack of fit value in the model is highly desirable. All of the responses fitted in the quadratic model showed a non-significant lack of fit $(p>0.1)$ except $Y_{3}$, proving the adequacy of the model fit. Table 4 shows a summary of the multiple regression analysis of the responses for the second-order quadratic model. The $\mathrm{R}^{2}$ values signify the measure of the amount of variation around the mean explained by the model. In this study, the $\mathrm{R}^{2}$ values for the 
responses $\mathrm{Y}_{1}, \mathrm{Y}_{2}$ and $\mathrm{Y}_{3}$ were $99 \%, 92 \%$ and $90 \%$, respectively. Signal-to-noise ratio, a measure of the range of a predicted response relative to its associated error, is called "adequate precision". For navigating the design space, a ratio greater than 4 is desirable. The ratios of "adequate precision" for $\mathrm{Y}_{1}, \mathrm{Y}_{2}$ and $\mathrm{Y}_{3}$ were 22.676, 7.397 and 8.508, respectively, indicating an adequate signal.
A

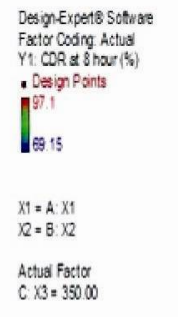

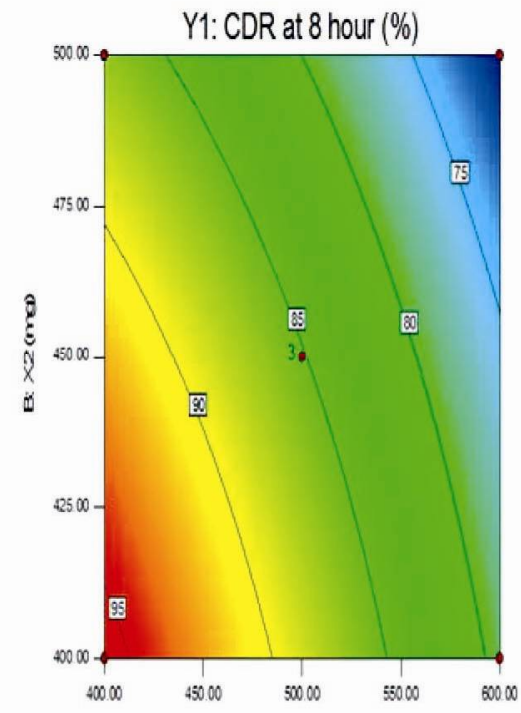

A X1 (mg)
B

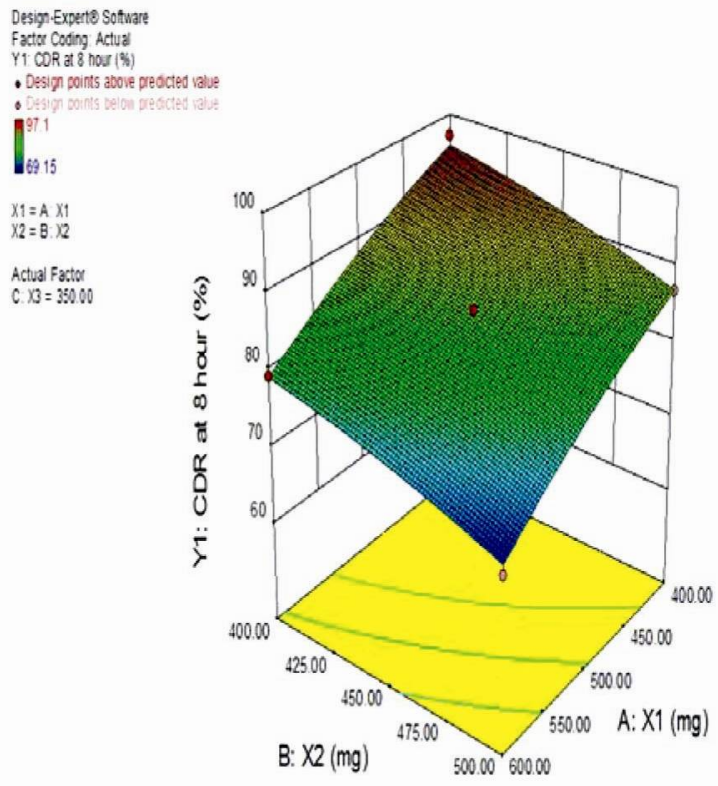

Figure 2. Effects of $X_{1}$ and $X_{2}$ on the \% CDR at 8 hour at the mid-level of $X_{3}$ : (A) contour plot and (B) its response surface.
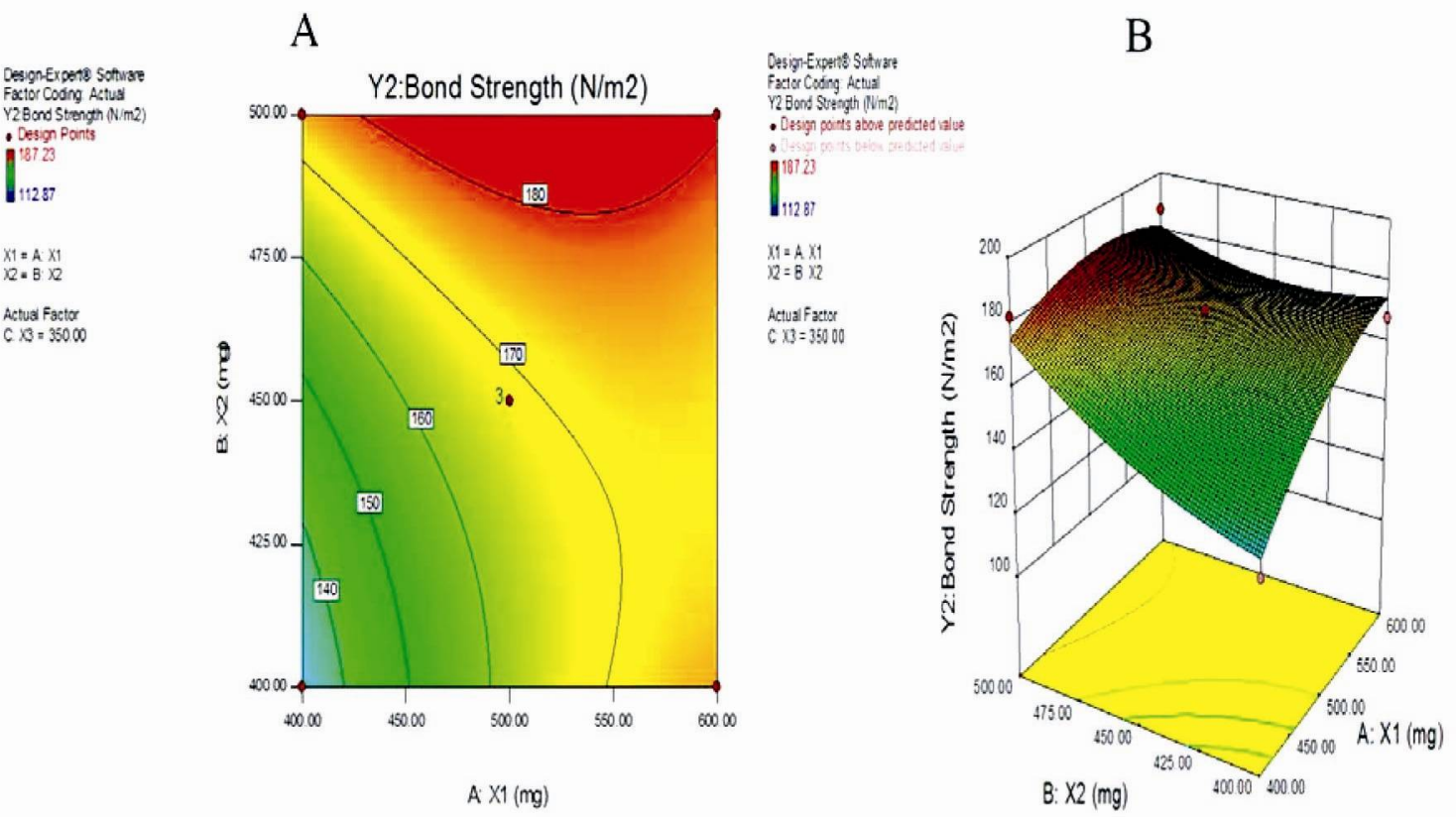

Figure 3. Effects of $X_{1}$ and $X_{2}$ on the bond strength $\left(N / \mathrm{m}^{2}\right)$ at the mid-level of $X_{3}$ : (A) contour plot and (B) its response surface. 


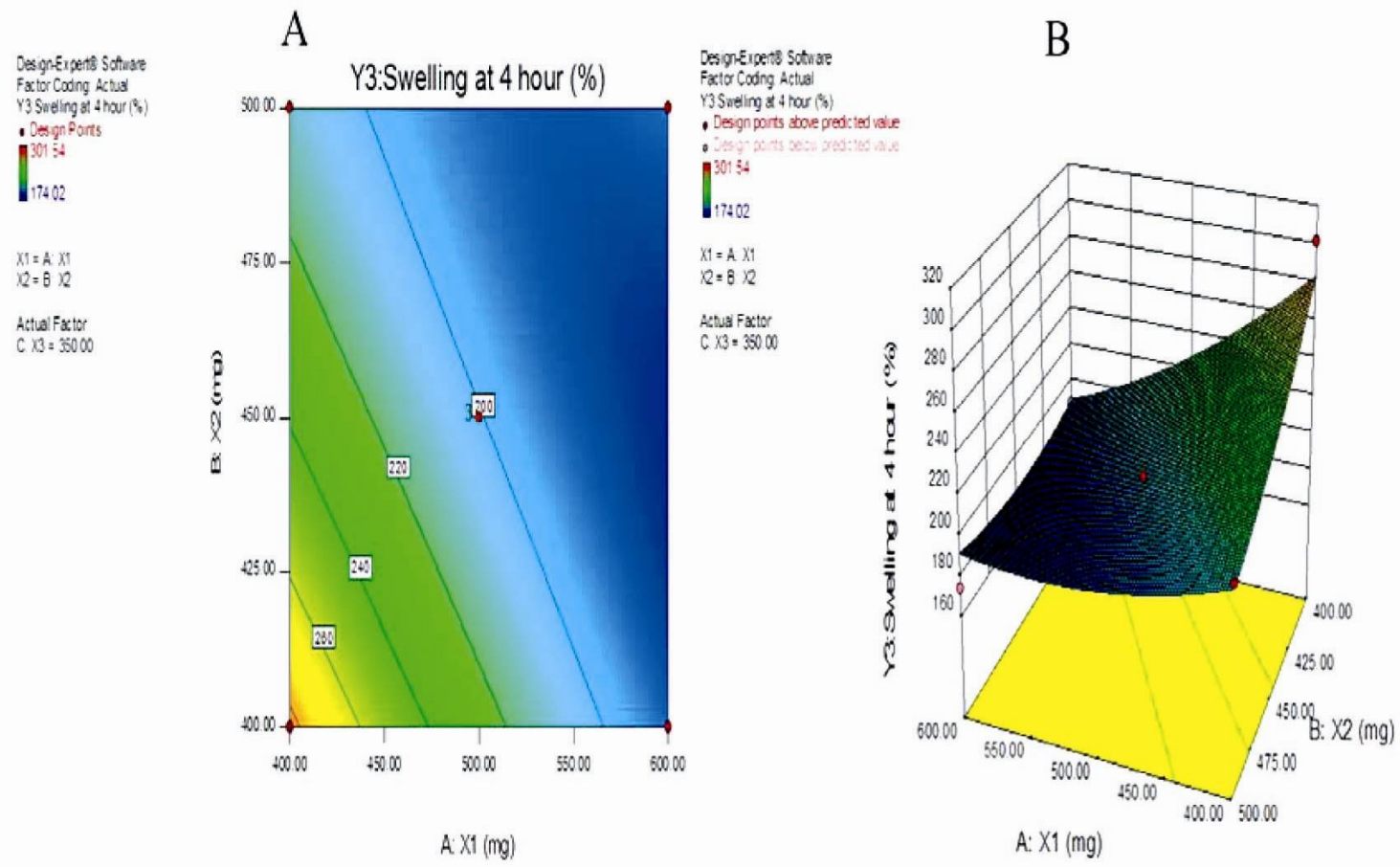

Figure 4. Effects of $X_{1}$ and $X_{2}$ on the \% swelling at 4 hour at the mid-level of $X_{3}$ : (A) contour plot and (B) its response surface.

A

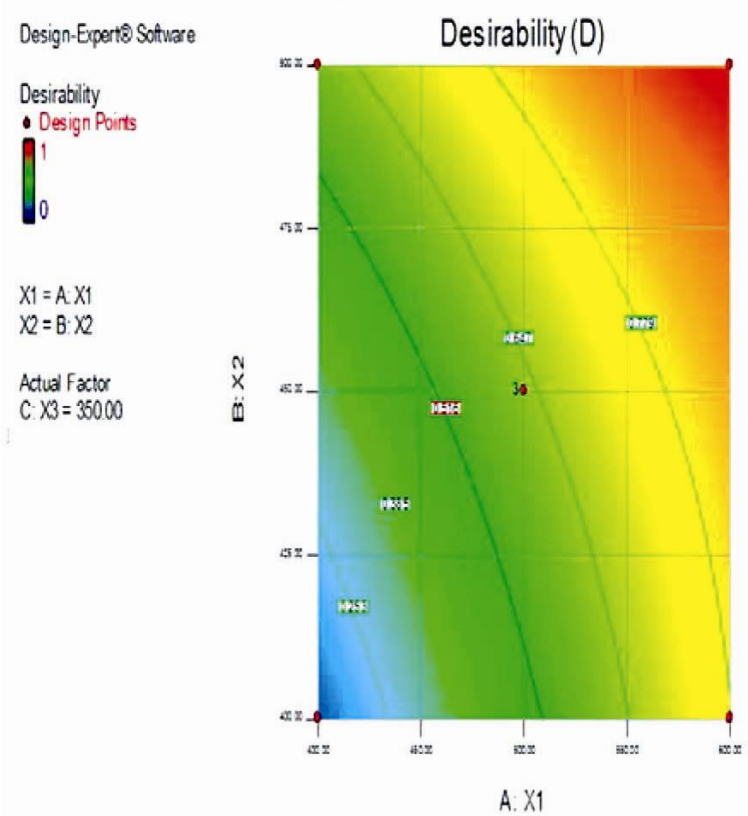

B

Design-Eperte Sotware

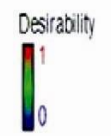

$X_{1}=A X_{1}$

$X 2=B: X 2$

Actual Factor

$C: X 3=3000$

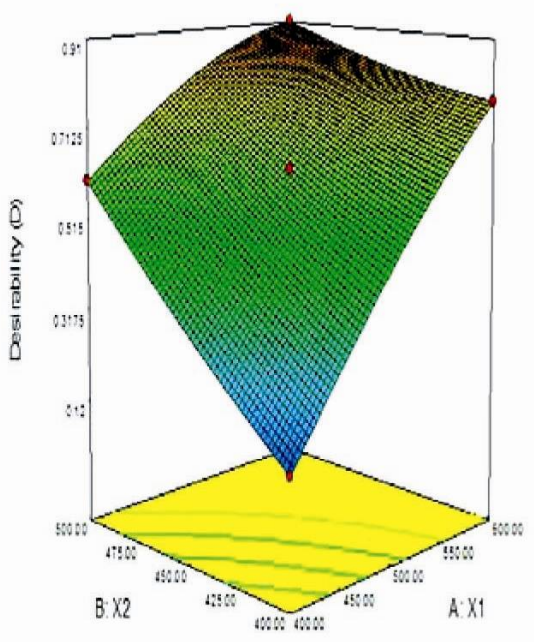

Figure 5. Overall desirability (D) as a function of $\mathrm{X}_{1}$ and $\mathrm{X}_{2}$ : (A) contour plot and (B) its response surface.

Coefficient estimation and equations for responses. The responses obtained at various levels of independent variables were subjected to multiple regression to give quadratic polynomial Eq. (5) for $Y_{1}$ in terms of coded factors where intercept is 85.19, coefficient value for $\mathrm{A}: \mathrm{X}_{1}$ is $-8.23, \mathrm{~B}: \mathrm{X}_{2}$ is -4.40 and $\mathrm{C}: \mathrm{X}_{3}$ is 1.43 ; quadratic polynomial Eq. (6) for $\mathrm{Y}_{2}$ in terms of coded factors where intercept is 168.20, 
coefficient value for $\mathrm{A}: \mathrm{X}_{1}$ is $12.03, \mathrm{~B}: \mathrm{X}_{2}$ is 12.28 and $\mathrm{C}: \mathrm{X}_{3}$ is -4.23 and quadratic polynomial Eq. (7) for $\mathrm{Y}_{3}$ in terms of coded factors where intercept is 200.71 , coefficient value for $\mathrm{A}: \mathrm{X}_{1}$ is $-28.04, \mathrm{~B}: \mathrm{X}_{2}$ is -17.81 and $\mathrm{C}: \mathrm{X}_{3}$ is 2.27 .

Table 3. ANOVA and lack of fit tests of the quadratic model for the responses.

\begin{tabular}{lcc}
\hline \multicolumn{1}{c}{ Response } & F Value & Probability $>F$ \\
\hline$Y_{1}$ & & \\
Model & 43.42 & $0.0003^{\mathrm{a}}$ \\
Lack of fit & 3.33 & $0.2393^{\mathrm{b}}$ \\
$\mathrm{Y}_{2}$ & & \\
Model & 6.66 & $0.0252^{\mathrm{a}}$ \\
Lack of fit & 1.71 & $0.3896^{\mathrm{b}}$ \\
$\mathrm{Y}_{3}$ & & \\
Model & 4.80 & $0.0495^{\mathrm{a}}$ \\
Lack of fit & 92.62 & $0.0107^{\mathrm{a}}$ \\
\hline
\end{tabular}

${ }^{\mathrm{a}}$ Significance probability values (Probability > F) less than 0.05 implies that the model is significant; ${ }^{\mathrm{b}}$ Nonsignificant lack of fit ( $p$ value > 0.1 ) proves the adequacy of model fit

Table 4. Summary of the regression analysis of the responses.

\begin{tabular}{lcccccc}
\hline Quadratic model & $\mathrm{R}^{2}$ & Adjusted $\mathrm{R}^{2}$ & Predicted $\mathrm{R}^{2}$ & Adequate precision & $\mathrm{SD}$ & $\mathrm{CV}(\%)$ \\
\hline $\mathrm{Y}_{1}$ & 0.9874 & 0.9646 & 0.8268 & 22.676 & 1.36 & 1.63 \\
$\mathrm{Y}_{2}$ & 0.9230 & 0.7845 & 0.0652 & 7.397 & 10.7 & 7.11 \\
$\mathrm{Y}_{3}$ & 0.8962 & 0.7093 & -0.6507 & 8.508 & 16.27 & 7.95 \\
\hline
\end{tabular}

$$
\begin{gathered}
\mathrm{Y}_{1}=85.19-8.23 \times \mathrm{A}-4.40 \times \mathrm{B}+1.43 \times \mathrm{C}+0.043 \times \mathrm{A} \times \mathrm{B}-0.44 \times \mathrm{A} \times \mathrm{C} \\
+0.57 \times \mathrm{B} \times \mathrm{C}-1.30 \times \mathrm{A}^{2}-0.81 \times \mathrm{B}^{2}-1.21 \times \mathrm{C}^{2} \\
\mathrm{Y}_{2}=168.20+12.03 \times \mathrm{A}+12.28 \times \mathrm{B}-4.23 \times \mathrm{C}-8.96 \times \mathrm{A} \times \mathrm{B}-4.48 \times \mathrm{A} \times \mathrm{C} \\
+1.00 \times \mathrm{B} \times \mathrm{C}-8.33 \times \mathrm{A}^{2}+6.11 \times \mathrm{B}^{2}-30.90 \times \mathrm{C}^{2} \\
\mathrm{Y}_{3}=200.71-28.04 \times \mathrm{A}-17.81 \times \mathrm{B}+2.27 \times \mathrm{C}+18.97 \times \mathrm{A} \times \mathrm{B}-0.86 \times \mathrm{A} \times \mathrm{C} \\
-1.89 \times \mathrm{B} \times \mathrm{C}+10.03 \times \mathrm{A}^{2}+8.08 \times \mathrm{B}^{2}-10.72 \times \mathrm{C}^{2}
\end{gathered}
$$

Response surface and contour plot analysis. To further elucidate the relationship between the independent and dependent variables, two dimensional contour plots and three-dimensional response surface plots of the responses across the selected factors were constructed as shown in figures 2, 3 and 4. These types of plots are very useful for studying the interaction effects between two factors and for understanding how the effect of one factor will be influenced by the change in the level of another factor. Here, one independent variable must always be fixed as these types of plots can only express two independent variables at a time against the response. ${ }^{27}$

Optimization and evaluation of the optimized formulation. The independent variables were simultaneously optimized for all three responses by using the desirability function after studying the 
effects of the dependent and independent variables on the responses. Responses $\mathrm{Y}_{1}, \mathrm{Y}_{2}$ and $\mathrm{Y}_{3}$ were transformed into individual desirability scales $d_{1}, d_{2}$ and $\mathrm{d}_{3}$, respectively. Constraints were set against all of the responses. Among the responses, $\mathrm{Y}_{2}$ was set to be maximized and $Y_{1}$ and $Y_{3}$ were set to be minimized. Equal weight and importance were given to all of the responses. Finally, by combining the individual desirability function as the geometric mean by abroad grid search and practicability search over the domain by the Design-Expert software (StatEase Inc.), the global desirability value was calculated. Figure 5 shows the response surface and counter plot for the desirability function holding the variable $X_{1}$ and $X_{2}$.

Table 5. Comparison of predicted and observed experimental values of acyclovir microspheres prepared under optimum conditions.

\begin{tabular}{lcccc}
\hline Responses & Predicted value & Observed value & Residuals & Bias* $(\%)$ \\
\hline $\mathrm{Y}_{1}(\%)$ & 69.99 & $65.57 \pm 3.15$ & -4.42 & 6.74 \\
$\mathrm{Y}_{2}\left(\mathrm{~N} / \mathrm{m}^{2}\right)$ & 181.18 & $178.81 \pm 2.64$ & -2.37 & 1.33 \\
$\mathrm{Y}_{3}(\%)$ & 191.29 & $185.10 \pm 7.53$ & -6.19 & 3.34 \\
\hline
\end{tabular}

$* \operatorname{Bias}(\%)=[($ predicted value - observed value $) \times 100] /$ observed value

The optimized formulation was achieved at $X_{1}=$ $600 \mathrm{mg}, X_{2}=500 \mathrm{mg}$ and $X_{3}=336.57 \mathrm{RPM}$ with the corresponding desirability (D) value of 0.917 . This factor level combination predicted the responses $Y_{1}=$ $69.99(\%), \mathrm{Y}_{2}=181.18 \mathrm{~N} / \mathrm{m}^{2}$ and $\mathrm{Y}_{3}=191.29 \%$. Finally, three batches of the optimized formulations were prepared to confirm the validity of the optimal parameters and predicted responses calculated. All of the responses were evaluated for each optimized formulation. The comparisons of predicted and experimental results are shown in table 5. It can be seen that the experimental values were in very close agreement with the predicted values, indicating the triumph of the BBD pooled with a desirability function for the assessment and optimization of acyclovir loaded microspheres formulations.

\section{CONCLUSION}

The present study lucratively demonstrated that using Methocel K15M and Ethocel Standard 45 Premium as polymeric materials, mucoadhesive microspheres, able to promote a sustained release of acyclovir were produced by emulsion-solvent evaporation technique which could be a smart solution to the pharmacokinetic limitation of acyclovir. The results obtained indicate that drug release can be slowed down by increasing polymeric concentration in the formulation. Moreover, for continuous drug delivery to the upper part of the gastrointestinal tract, mucoadhesion could be a resolution by means of applying Methocel K15M in the formulation. Furthermore, the study successfully verified the use of the BBD combined with a desirability function for the optimization of different responses of acyclovir loaded microspheres since the observed values were found to be in close agreement with the estimated values. Response surface plots and contour plots were used to study the effects of different formulation variables on the responses and the results obtained suggest that the RSM using the BBD could be a suitable approach for understanding formulation variables and for optimizing the formulation efficiently. However, this study only investigated on in vitro and ex vivo settings. Further study focusing on in vivo settings can be taken into consideration for better predictability of drug delivery in a biological system.

\section{ACKNOWLEDGEMENT}

Authors are grateful to their designated institute for providing the necessary facilities to accomplish the research work. Incepta Pharmaceuticals Ltd, Bangladesh is gratefully acknowledged for providing with the active ingredient. 


\section{CONFLICT OF INTEREST}

The authors declare that there is no conflict of interests regarding the publication of this paper.

\section{REFERENCES}

1. Tiwari, G., Tiwari, R., Sriwastawa, B., Bhati, L., Pandey, S., Pandey, P. and Bannerjee, S.K. 2012. Drug delivery systems: an updated review. Int. J. Pharm. Investig. 2, 2-11.

2. Vasir, J.K., Tambwekar, K. and Garg, S. 2003. Bioadhesive microspheres as a controlled drug delivery system. Int. J. Pharm. 255, 13-32.

3. Singh, B., Kumar, R. and Ahuja, N. 2005. Optimizing drug delivery systems using systematic "design of experiments" part I: fundamental aspects. Crit. Rev. Ther. Drug Carrier. Syst. 22, 27-106.

4. Singh, B., Bhatowa, R., Tripathi, C.B. and Kapil, R. 2011. Developing micro-/nanoparticulate drug delivery systems using" design of experiments". Int. J. Pharm. Investig. 1, 7587.

5. Marasini, N., Yan, Y.D., Poudel, B.K., Choi, H.G., Yong, C.S. and Kim, J.O. 2012. Development and optimization of self-nanoemulsifying drug delivery system with enhanced bioavailability by Box-Behnken design and desirability function. J. Pharm. Sci. 101, 4584-4596.

6. Ferreira, S.C., Bruns, R.E., Ferreira, H.S., Matos, G.D., David, J.M., Brandao, G.C., da Silva, E.P., Portugal, L.A., Reis, P.S.D., Souza, A.S. and Santos, W.N.D. 2007. BoxBehnken design: an alternative for the optimization of analytical methods. Anal. Chim. Acta. 597, 179-186.

7. Kim, M.S., Kim, J.S., You, Y.H., Park, H.J., Lee, S., Park, J.S., Woo, J.S. and Hwang, S.J. 2007. Development and optimization of a novel oral controlled delivery system for tamsulosin hydrochloride using response surface methodology. Int. J. Pharm. 341, 97-104.

8. Bodea, A. and Leucuta, S.E. 1998. Optimization of propranolol hydrochloride sustained-release pellets using box-behnken design and desirability function. Drug Dev. Ind. Pharm. 24, 145-155.

9. Kyada, C., Ranch, K. and Shah, D. 2014. Optimization of mucoadhesive microspheres of acyclovir by applying $3^{2}$ full factorial design. J. Drug Deliv. Sci. Tech. 24, 61-68.

10. Tao, Y., Lu, Y., Sun, Y., Gu, B., Lu, W. and Pan, J. 2009. Development of mucoadhesive microspheres of acyclovir with enhanced bioavailability. Int. J. Pharm. 378, 30-36.

11. Bhosale, U.V., Devi, K. and Choudhary, S. 2012. Multiunit floating drug delivery system of acyclovir: development, characterization and in vitro-in vivo evaluation of spray-dried hollow microspheres. J. Drug Deliv. Sci. Tech. 22, 548-554.
12. Jalón, E.G., Blanco-Prí, M.J., Ygartua, P. and Santoyo, S. 2003. Increased efficacy of acyclovir-loaded microparticles against herpes simplex virus type 1 in cell culture. Eur. J. Pharm. Biopharm. 56, 183-187.

13. Rokhade, A.P., Patil, S.A. and Aminabhavi, T.M. 2006. Synthesis and characterization of semi-interpenetrating polymer network microspheres of acrylamide grafted dextran and chitosan for controlled release of acyclovir. Carbohydr. Polym. 67, 605-613.

14. Jana, S., Sharma, R., Maiti, S. and Sen, K.K. 2016. Interpenetrating hydrogels of O-carboxymethyl tamarind gum and alginate for monitoring delivery of acyclovir. Int. J. Biol. Macromol. 92, 1034-1039.

15. Dhaliwal, S., Jain, S., Singh, H.P. and Tiwary, A.K. 2008. Mucoadhesive microspheres for gastroretentive delivery of acyclovir: in vitro and in vivo evaluation. The AAPS J. 10, 322-330.

16. Akhter, S., Paul, S., Hasan, I., Ayon, N.J., Haider, S.S. and Reza, M.S. 2013. Preparation, characterization and compatibility studies of naproxen loaded microspheres of cellulosic and polymethacrylic polymeric blend. Dhaka Univ. J. Pharm. Sci. 12, 11-21.

17. Ayon, N.J., Hasan, I., Islam, M.S. and Reza, M.S. 2014. Preparation and characterization of gliclazide incorporated cellulosic microspheres: studies on drug release, compatibility and micromeritics. Dhaka Univ. J. Pharm. Sci. 13, 149-166.

18. Saha, N., Hasan, I., Nazmi, M. and Reza, M.S. 2013. Design and development of sustained release microspheres of ibuprofen by emulsification solvent evaporation method using polymeric blend. Bangladesh Pharm. J. 16, 39-44.

19. Derringer, G. and Suich, R. 1980. Simultaneous optimization of several response variables. J. Qual. Technol. 12, 214-219.

20. Vinodbhai, P.K., Gohel, M.C., Parikh, R.K., Bariya, S. and Suthar, R.N. 2011. Sustained release floating microspheres of acyclovir: formulation, optimization, characterization and in vitro evaluation. Int. J. Drug Dev. Res. 3, 242-251.

21. Md, S., Ahuja, A., Khar, R.K., Baboota, S., Chuttani, K., Mishra, A.K. and Ali, J. 2011. Gastroretentive drug delivery system of acyclovir-loaded alginate mucoadhesive microspheres: formulation and evaluation. Drug Deliv. 18, 255-264.

22. Jalil, R. and Nixon, J.R. 1990. Microencapsulation using poly (1-lactic acid) II: preparative variables affecting microcapsule properties. J. Microencapsul. 7, 25-39.

23. Freiberg, S. and Zhu, XX. 2004. Polymer microspheres for controlled drug release. Int. J. Pharm. 282, 1-18.

24. Meadows, K.C. and Dressman, J.B. 1990. Mechanism of acyclovir uptake in rat jejunum. Phar. Res. 7, 299-303. 
5. O'Brien, J.J. and Campoli-Richards, D.M. 1989. Acyclovir: an updated review of its antiviral activity, pharmacokinetic properties and therapeutic efficacy. Drugs. 37, 233-309.

26. Park, G.B., Shao, Z. and Mitra, A.K. 1992. Acyclovir permeation enhancement across intestinal and nasal mucosae by bile salt-acylcarnitine mixed micelles. Pharm. Res. 9, 1262-1267.
27. Wu, X.G., Li, G. and Gao, Y.L. 2006. Optimization of the preparation of nalmefene-loaded sustained-release microspheres using central composite design. Chem. Pharm. Bull. 54, 977-981. 